\title{
CORRIGENDUM
}

\section{Abl inhibitor BMS354825 binding mode in Ableson kinase revealed by molecular docking studies}

C Gambacorti-Passerini, M Gasser, S Ahmed and L Scapozza

Leukemia (2005) 19, 2023. doi:10.1038/sj.leu.2403990

Correction to: Leukemia (2005) 19, 1267-1269.

doi: $10.1038 /$ sj.leu.2403775

It has been realised by the authors that incorrect labelling has been used in Figure $1 \mathrm{~b}$ right panel (ligplot of the intermediate conformation), the labelling should read: the aspartate that hydrogen bonds the hydroxyl group of BMS is D325 and not D381 as printed. Please find below the correct labelling and figure.

The authors apologise for this error.

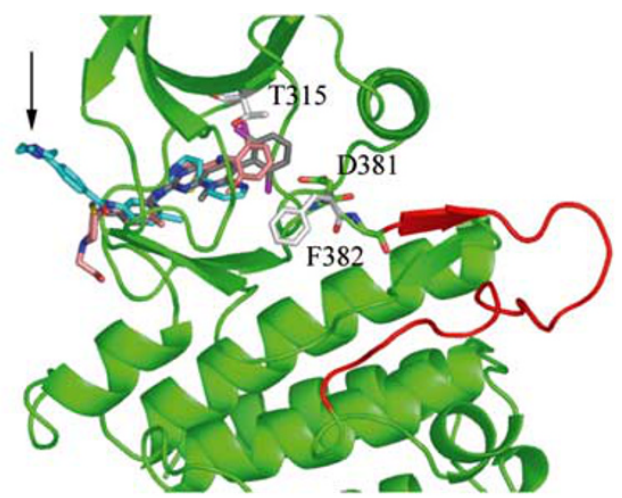

b
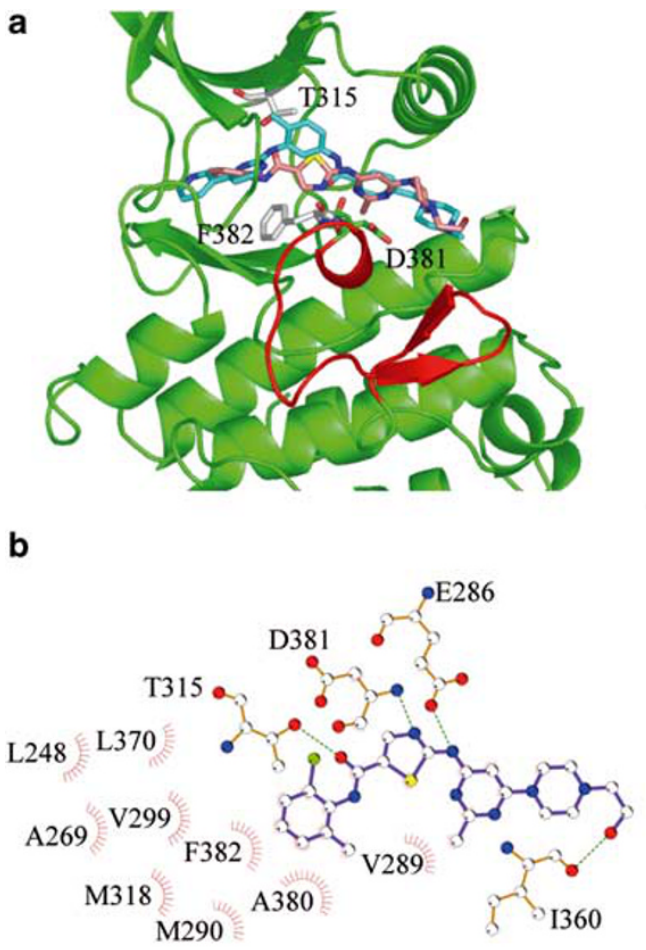

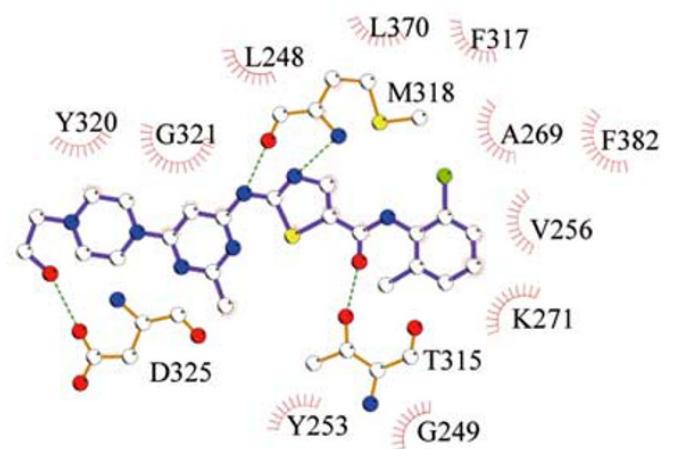

